\title{
Cenários do Pantanal: o gado, os peões e as comitivas
}

\author{
Eron Brum*
}

As Comitivas Pantaneiras, herdeiras dos Tropeiros, existem há pelo menos 200 anos, coincidindo com o início do desenvolvimento da pecuária enquanto atividade econômica embrionária no então Estado de Mato Grosso. Poucas e precárias estradas dificultavam ao longo do século XIX até meados do século XX, o deslocamento das tropas, trabalho realizado pelos tropeiros/boiadeiros, ainda não organizados em comitivas. A abertura de estradas e a preferência de alguns setores econômicos pelo transporte de gado em caminhões, inicialmente causou temor entre os peões, mas o tempo mostrou que as Comitivas continuam imbatíveis no transporte de gado, especialmente no período de cheias. Este ensaio, além de pretender resgatar um pouco da memória e cultura das Comitivas, registrou o cotidiano do peão pantaneiro, autêntico profissional especializado nessa atraente e desafiadora região.

Palavras-Chave: Boiadeiros, Pantanal, Pecuária.

The Pantaneira Entourages, Tropeiros heiresses, exists at least 200 years, coinciding with the beginning of the development of livestock as an embryonic economic activity in
A té o século XVII, o Pantanal era conhecido como Xarayes, nome de uma nação indígena. Mais tarde, vindo a ser chamado de pantanal ou pantanaes, pelos portugueses. Planície de 220 mil quilômetros quadrados, grande parte cercada por montes, como, por exemplo, as serras de Maracaju, das Araras e de Bodoquena. Como define Adámoli ${ }^{1}$. A oeste a região faz divisa com Bolívia e Paraguai. Acredita-se que o Pantanal se originou há milhões de anos, da redução do suposto mar Platino a essa área inundável. O seu solo, composto de areias quaternárias e terrenos calcários, ao contrário do que se pensa e apesar do nome, não é considerado um pântano. A região tem duas estações bem definidas: seca e cheia. No período da cheia - entre novembro e

\footnotetext{
* Eron Brum é Jornalista, Professor Titular aposentado pela Universidade Federal de Mato Grosso do Sul(UFMS) e Doutor em Ciências da Comunicação pela Universidade de São Paulo(USP). Exprofessor no Mestrado de Meio Ambiente e Desenvolvimento Regional. Uniderp/Anahnguera. eron.brum@hotmail.com
}

${ }^{1}$ ADÁMOLI, Jorge. Diagnóstico do pantanal (Características ecológicas e problemas ambientais). Brasília, DF: IBAMA/PNMA, 1991. 
the state of Mato Grosso. Few and poor roads made the movement of troops, work done by cowboys / ranchers, not organized yet into caravans, difficult during the nineteenth century until the mid-twentieth century. The opening of roads and the preference of some economic sectors for the transport of cattle trucks, caused fear among laborers in the beginning, but time has shown that Entourages continues to be unbeatable in the transport of livestock, particularly during the floods. This essay, besides of rescueing a little of memory and culture of Entourages, registered the daily life of the laborer wetland, specialized authentic professional in this attractive and challenging area.

Key words: Ranchers, Pantanal, Livestock.

março - os rios transbordam e cerca de 150 mil quilômetros de extensão mitificam submersos.

Há áreas mais afastadas, nas quais a enchente atinge apenas as depressões, formando lagoas e baias. Os pantaneiros denominam as terras não alagadas, situadas nessa região, de cordilheiras. Elas são bom local para colocar o gado que, nessa época, chega a pastar o capim que fica coberto pela d'água. Durante as cheias as fazendas ficam ilhadas e as canoas passam a substituir cavalos. Rios e corixos - desvios temporários dos rios e córregos - se tornam estradas e a vegetação cresce a ponto de fechar as passagens.

Proença ${ }^{2}$ observa que a terra guarda a moleza das primeiras idades. Os rios ainda mudam de lugar. As águas são espraiadas, como se o terreno houvesse permanecido jovem demais, para que os rios tivessem tido tempo de escavar seus leitos". Os anos de 1812, 1865, 1895, 1900, 1905, 1912 e 1920 registraram algumas das maiores enchentes no Pantanal, sendo a de 1905 a maior de todas, assegura $\mathrm{Baez}^{3}$. Nesse ano as águas ficaram a 2 metros de altura do porto do município de Corumbá. Entre 1974 e 1977, as cheias também foram marcantes.

É no cenário do período das cheias que as Comitivas Pantaneiras ganham maior visibilidade, já que são a única possibilidade de conduzir o gado em direção aos frigoríficos, leilões ou mesmo para os locais não atingidos pela água. Proença ${ }^{4}$ alerta que o Pantanal não é um mundo cor-de-rosa, como a mídia tanto propaga.

\footnotetext{
${ }^{2}$ PROENÇA, Augusto César. Raízes do pantanal. Belo Horizonte: Itatiaia, 1989.

${ }^{3}$ BAEZ, Renato. Corumbá: episódios e comentários. São Paulo: Resenha Tributária, 1979

${ }^{4}$ PROENÇA, Augusto César. Pantanal: gente, tradição e história. $3^{\text {a }}$. Ed. Campo Grande: EdUFMS, 1997.
} 
Quem vive no Pantanal e depende dele sabe o quanto é difícil adaptar-se a essa natureza inconstante.

As Comitivas Pantaneiras - mostradas de forma fragmentada e romântica pelos escritores regionais e cantada em tons heróicos na chamada música caipira -, duzentos anos depois de seu aparecimento como atividade de suporte econômico da pecuária, vive um novo momento histórico. Os primeiros registros dos comitiveiros coincidem com o início do desenvolvimento da pecuária enquanto atividade econômica embrionária no então Estado de Mato Grosso, e quase sempre falam das poucas e precárias estradas que dificultavam, ao longo do século XIX até meados do século XX, o deslocamento das tropas, trabalho realizado pelos tropeiros ou boiadeiros, ainda não organizados em comitivas, enfatiza Brum ${ }^{5}$.

Nesta etapa da pesquisa - acompanhamento das Comitivas Pantaneiras optou-se pelo de pesquisa qualitativa conforme as recomendações de $\mathrm{Uwe}^{6}$, e as técnicas empregadas foram pesquisa-ação e entrevistas semi-estruturadas, ambas defendidas por Bauer e Gaskel17 quando se busca aprofundamento de temas complexos e de teoria pouco reveladora.

No início do século passado os tropeiros começaram se estruturar em Comitivas, já que a pecuária, no mesmo período, ganhou status de atividade econômica relevante, principalmente com a chegada ao Estado de colonizadores do Sul - predominância de gaúchos. Porém, a abertura de estradas e a preferência pelo transporte do gado em caminhões causou forte impacto nas atividades das comitivas, em especial nas regiões do Planalto.

O transporte do gado em caminhões, chamados de Gaiolas Boiadeiras, através da Transpantaneira, e a realização de leilões em áreas perto de rodovias, também fizeram com que as comitivas, de certa forma, perdessem algum espaço. Em 1974, o Governo Federal deu início ao Programa Especial de Desenvolvimento do Pantanal, para construir a estrada, com finalidade de criar facilidade para a exportação de bovinos, que passou a poder ser feita em qualquer período do ano, sem tantas dificuldades.

\footnotetext{
${ }^{5}$ BRUM, Eron (org.). A mídia do pantanal. Campo Grande: EdUNIDERP, 2001.

${ }^{6}$ FLIK, Uwe. Uma introdução à pesquisa qualitativa. 2a . Ed. Porto Alegre: Ed. Boockman, 204.

${ }^{7}$ BAUER, Martin W., GASKELL, George. Pesquisa qualitative com texto, imagem e cor. Um manual prático. $4^{\mathrm{a}}$. Ed. Petrópolis: Vozes, 2002.
} 
Outro fato que trouxe descontentamento aos integrantes de comitivas é a diferença entre o tratamento que recebiam há algum tempo e o que é dispensado a eles hoje nas fazendas pelas quais passam em suas jornadas. Vários herdeiros e os novos compradores das terras pantaneiras têm uma visão empresarial e agem de acordo com ela. Eles cobram pela alimentação, hospedagem, mercadorias e até mesmo pelo pasto, decepcionando boiadeiros e condutores.

Mas o fracasso da construção da Transpantaneira - até hoje uma obra inacabada - pouco afetou, ao contrário do que se poderia pensar, as atividades das Comitivas Pantaneiras, notadamente no período das cheias, onde continuam imbatíveis. Acrescente-se o surgimento dos leilões de gado, as exposições agropecuárias e a importância cada vez mais acentuada da Pecuária como uma das principais atividades econômicas do Estado de Mato Grosso do Sul.

Os grandes fazendeiros tradicionais do Pantanal mantêm contrato permanente com as Comitivas. É o caso do médico-veterinário Fernando Bumlai, proprietário de fazendas nos pantanais de Paiaguás e Nhecolândia: "Dependendo da época, das enchentes periódicas e do momento econômico chego a trabalhar com até oito comitivas ao mesmo tempo. Apesar do surgimento dos caminhões de transporte de gado, as gaiolas boiadeiras, as comitivas são insubstituíveis por motivos funcionais e econômicos".

Vagner Mourão, 57 anos vivendo no Pantanal, ex-fazendeiro e hoje proprietário e condutor de Comitivas, dá exemplos não apenas da importância da atividade na cadeia produtiva da carne, mas destaca as suas múltiplas funções em razão do progresso: "Deixei a fazenda de meu pai no Pantanal do Nhecolândia por ocasião da inauguração do leilão da Estrada Parque, perto do Paço do Lontra. Organizei minha primeira comitiva e passava de fazenda em fazenda recrutando o gado para ser vendido no leilão. E nunca mais parei”.

A Comitiva do Mourão, como é conhecida principalmente nos pantanais de Paiaguás e Nhecolândia, tem trabalho o ano inteiro. A estrutura é de uma pequena empresa: em sua casa, no município de Corumbá, a esposa seus dois filhos não descuidam do telefone, pois a qualquer momento pode surgir uma nova viagem. "A vida de comitiva é dura, mas é o que sei e gosto de fazer. E trabalho não falta, pois além de levar gado para os leilões ou para ser embarcado nas gaiolas boiadeiras, muitos fazendeiros precisam deslocar o gado durante as enchentes em busca de terrenos mais secos e, depois, realizar o trajeto de volta". 
Bumlai confirma as observações de Mourão: "Os comitiveiros conhecem profundamente a realidade do Pantanal. Além disso, o transporte a longas distâncias em caminhões pode inviabilizar economicamente a atividade pecuária. Por exemplo, um trabalho realizado pelas comitivas em um trajeto de $600 \mathrm{~km}$, que custa $\mathrm{R} \$ 6.6000,00$, pode chegar até as $\mathrm{R} \$ 35$ mil nos caminhões”.

Edite Araújo Cardoso, talvez a única mulher proprietária de comitiva em Mato Grosso do Sul, reside em Campo Grande, tem três comitivas e não pensa e abandonar o trabalho antes exclusivo dos homens. "São 24 peões e 77 animais entre burros, mulas e petiços. Os gastos são altos, mas compensa. Hoje temos muito trabalho e até bem pouco tempo eu tinha apenas uma comitiva. É uma atividade como outra qualquer e não enfrento problemas só pelo fato de ser mulher. Durmo em rede, acordo de madrugada para o chimarrão, tomo café, almoço e janto com os peões e todos me respeitam muito", afirma a ágil e forte dona de Comitiva Nova Era que tem orgulho em dizer que sua filha formou-se em Biologia em uma Universidade de Campo Grande graças às comitivas e ao trabalho de seu marido, capataz de uma fazenda no Pantanal de Nhecolândia.

Outro aspecto destacado por profissionais do mercado agropecuário é a exigência cada vez mais sofisticada dos consumidores da carne, especialmente os europeus. O transporte em caminhões pode abalar a saúde do gado, não apenas física, mas o estresse também é motivo de preocupações. Exageros? Do ponto de vista do profissional de comitivas, Vagner Mourão, as gaiolas boiadeiras não são concorrentes:

"É muito mais saudável o transporte pelas comitivas, pois o gado vai pastando, bebendo água, não sofre. Em quase todo o Pantanal há mangueiros especiais para o pernoite. E mesmo nas estradas os problemas são poucos, os motoristas entendem nosso trabalho e respeitam, colaboram e raramente temos perda de animais. As longas distâncias e as águas do Pantanal são os nossos maiores aliados. Por isso eu conto pro senhor que enquanto existir Pantanal existirão comitivas".

Na relação entre fazendeiros e donos das comitivas a palavra, artigo cada vez mais raro neste mundo globalizado, tem o valor de um contrato assinado e registrado em cartório. A tradição dos pantaneiros é uma moeda valiosa e ninguém ousa falar do "papel assinado" para fechar um negócio. O mercado das comitivas é regulado de acordo com as várias atividades, mas pode-se afirmar que há duas grandes funções desempenhadas pelas comitivas: a do transporte, 
nascido com os boiadeiros há dois séculos, e outra mais recente, o manejo de gado no interior das fazendas, antes tarefa dos peões contratados.

O transporte de gado é o mais visível e, por isso mesmo, bem conhecido. São as comitivas que partem das fazendas do Pantanal com destino aos leilões, aos frigoríficos ou às outras fazendas. Com o aumento do rebanho no Estado os fazendeiros necessitam de muitos peões para a identificação dos bezerros recém-nascidos, a vacinação, o embarque nas gaiolas, manejo no período das cheias e a solução mais econômica é a contratação das comitivas. O pagamento também acompanha as características de cada atividade. Pelo transporte de longas distâncias o contrato entre fazendeiro e comitiveiro oscila entre $\mathrm{R} \$ 300,00$ a $\mathrm{R} \$ 350,00$ diários. Os peões recebem, em média $\mathrm{R} \$ 450,00$ mensais. No trabalho interno das fazendas esses valores ficam um pouco abaixo e o argumento é forte: trata-se de emprego certo por longos períodos e não apenas contrato temporário, ou "por viagem".

\section{A estrutura eficiente das comitivas}

A tropa das Comitivas Pantaneiras, formada por burros e mulas ou eqüinos, é de propriedade do condutor. Os primeiros são utilizados, em geral, para viagens longas, pois apesar de não serem velozes, são bastante resistentes. Já o cavalo é mais rápido, mas precisa de maior descanso e enfrenta dificuldades nas áreas que se alternam secas e enchentes. Até o cavalo pantaneiro, mais adaptado à região, sofre rejeição por parte dos peões. Na maioria das vezes, o número de animais de montaria, levado em uma comitiva é, pelo menos, de três a quatro vezes superior ao de peões.

Ao receber o gado, os peões contam quantas cabeças transportarão e analisam o comportamento dos animais e vêem quais bois darão mais trabalho, para montarem sua estratégia. De madrugada eles encilham os animais de montaria, verificavam todos os apetrechos, laços, peias, manoplas, alforjes, guampas e redes.

Sal, açúcar, carne-seca, arroz, farinha e mate, em pequena quantidade geralmente são levados, no lombo de cavalos. Ervas medicinais também são transportadas para serem utilizados em caso de alguém ser picado por algum animal vene- 
noso, adoecer, ou se machucar. Antes de sair para o campo os boiadeiros tomam apenas café, chimarrão e às vezes guaraná em pó.

As Comitivas Pantaneiras continuam ocupando seu espaço com a formação clássica de sete peões: na retaguarda do gado, o condutor, capataz ou culatreiro, quase sempre o proprietário da comitiva ou então contratado pelo fazendeiro dono do gado. $\mathrm{O}$ condutor é o mais experiente dos peões e cabe a ele contratar o pessoal e formar a comitiva.

Dos lados esquerdo e direito, logo a frente do condutor, seguem os meeiros, responsáveis pelo bom andamento da primeira metade tropa. À frente da boiada posiciona-se ponteiro, a grande estrela da comitiva. Sempre com o berrante nas mãos - instrumento de sopro feito de chifre de boi - alerta os demais companheiros com uma grande variedade de toques para perigos sempre constantes que rondam o gado.

O ponteiro é um exímio cavaleiro e conhecedor dos sinais do meio ambiente pantaneiro. Ele avisa, por exemplo, da presença de onças, dos enxames de abelha que podem provocar o chamado estouro da boiada. É ladeado pelos fiadores, seus auxiliares diretos e que cuidam da metade da frente da comitiva.

Completam a equipe o solitário cozinheiro, sempre alguns quilômetros distante da boiada. O cozinheiro deixa a comitiva de madrugada, carrega os animais com as bruacas - tipo de baú feito de madeira e coberta com couro de boi - cheias de alimentos e espera os companheiros cerca de $10 \mathrm{~km}$ adiante, para o almoço. Repete o ritual no período da tarde e prepara o jantar. "Quando é muito gado, mais de mil cabeças, e o trajeto quase todo às margens das estradas asfaltadas, algumas comitivas incluem dois bandeirinhas, aqueles cavaleiros que, portando pequenas bandeiras vermelhas, alertam os motoristas", complementa Vagner Mourão.

A difícil tarefa de conduzir a boiada pelo Pantanal exige muita prática. Clima, estrada, animais selvagens, doenças e humor da boiada são elementos que interferem no passo da comitiva. A forma como a comitiva é organizada serve como segurança para que a boiada não se disperse.

O trabalho nas Comitivas começa com o nascer do sol. A primeira parada é entre onze horas e meio dia; o ponteiro dá um sinal à tropa de que ela está se 
aproximando do local combinado com o cozinheiro. Neste horário, o gado já está mais vagaroso. Os peões tocam os bois para o lado daqueles que já estão parando, há alguns, inclusive, que até se deitam no chão.

Os peões desencilham os animais antes do almoço. Na hora da refeição eles devem tirar o chapéu. O primeiro a se servir é o condutor. Já alimentados, os viajantes tiram a sesta enquanto o cozinheiro junta os objetos da cozinha e segue viagem até o local da segunda parada, onde a tropa irá passar a noite em mangueiros de fazendas ou mesmo em campo aberto.

Não deve predominar o silêncio durante o andar da comitiva, pois ele causa sono aos animais, mas muita movimentação também deve ser evitada. Os boiadeiros se comunicam com o gado através de gritos, estalos do arreador e do som do berrante, para que ele não se disperse. Normalmente a comitiva percorre 20 quilômetros por dia.

\section{Peoa Loira desafia o preconceito}

Mulher em comitiva é a mesma coisa que encontrar "agulha no palheiro", comentam os peões. Se presença de Dona Edith, proprietária de três comitivas que cruzam o Pantanal o ano inteiro já é uma raridade, imagine uma peoa no meio dos homens rudes sob sol quente ou chuva enfrentando as durezas pantaneiras?

Mirelle Oliveira Gueller, uma loira esguia, bonita e vaidosa nasceu em Fátima do Sul, cidade do interior de Mato Grosso do Sul. Aos quatro anos, quando seus pais se separaram ela ficou sob a guarda do pai, Nelson Gueller. Alguns anos depois seu pai começou a viajar em comitivas e tentou deixar a filha com a mulher de um dos peões. Mirelle recusou na hora, queria ficar junto do pai. Era o início de sua vida de peoa, uma raridade nesse tipo de profissão, contam Oliveira e Zardo ${ }^{8}$.

A vida de Mirelle parece uma história de ficção. Ao completar nove anos sua mãe ganhou na Justiça o direito de ficar com a filha. Mas, aos 14 anos, decidiu

\footnotetext{
${ }^{8}$ A entrevista com a peoa Mirelle Oliveira Gueller foi realizada pelas acadêmicas de Jornalismo/ Uniderp, OLIVEIRA, Camyla Campos e ZARDO, Maria Irene de Souza. Guerreiros do Xarayes (trabalho de conclusão de curso). Campo Grande: Ed.Uniderp, 2004. Orientador: Dr. Eron Brum.
} 
retornar à comitiva do pai. Arrumou a mala e saiu à procura do pai e, ao encontrálo, disse: "Hoje eu vô vortá a sê feliz, do seu lado".

É difícil acreditar que uma moça meiga, de cabelos longos e sempre sorridente pudesse ter optado por uma profissão tão desgastante, a de boiadeira. As más línguas chegaram a difamar Mirelle, pois, nesse ramo, praticamente não há espaço para mulheres. Ela não se importa, faz o que gosta e é feliz: "Quero morrê na estrada, no lombo dum burro", diz com orgulho.

Mirelle aprendeu cedo a tocar berrante, chega até a tirar alguns acordes do Hino Nacional. E mesmo demonstrando determinação e fazendo os mesmos serviços que os outros peões, seu pai tentou fazê-la desistir. Não adiantaram os sustos durante as longas viagens, ter de tomar banho na beira dos rios tarde da noite, depois que todos os homens já estavam dormindo. Seu grande prazer é viajar pelas areias e águas do traiçoeiro Pantanal no lombo de um burro.

E para demonstrar sua personalidade forte, um dia brigou com o pai e foi trabalhar em outra comitiva. Ela conta com um sorriso malicioso no rosto algumas histórias dos peões. "Quando mudei de comitiva sempre aparecia um cavalheirozinho por perto prá me ajudá. Mas depois eles desistiam, percebiam que sei fazer tudo o que eles fazem".

Mesmo com todas as dificuldades a boiadeira procura se cuidar da maneira como pode. Xampu e creme estão sempre em sua bagagem. Além disso, tenta manter limpas as suas roupas: "Não tenho mais aquela vaidade de trocar de roupa todos os dias, mas eu lavo a cada dois ou três dias". Mas confessa que em certas ocasiões gosta de se arrumar: "Quando tenho que ver um moreno bonito eu me cuido mais um pouquinho".

Mirelle garante que não namora peão de sua comitiva: "Tem uns peões que dá uma cantadinha, acham que vão me conquistá. Dou logo um chega prá lá e eles desistem. E assim levo a vida, numa boa". Casar, ter filhos? Mirelle sonha com isso, mas impõe uma condição: "Eu tava namorando um peão de outra comitiva e ele propôs que a gente deixasse a estrada e fosse trabalhar em uma fazenda, ficava mais fácil. Terminei o namoro na hora, meu negócio é andar pelo Pantanal atrás da boiada".

A peoa lamenta a ausência da mãe na sua infância, mas confessa que sua grande paixão é pelo pai. Como trabalham em comitivas diferentes, fica meses 
sem encontrá-lo: “Ah, dá um aperto no coração. Tem dia que a gente amanhece bem, tem dia amanhece mal. Longe da família, perto de peão que nem parente é. Aí dá uma vontade de chorá...”.

\section{Lamento, nostalgia e tristeza na inúsica regional}

Comitiva Esperança, Estrada de Chão e Pelo Rádio são composições de artistas regionais - Paulo Simões, Aurélio Miranda, Celito e Geraldo Espíndola - que retrata as alegrias e as tristezas, as mágoas e as aventuras, a nostalgia e a esperança dos peões pantaneiros.

É a música caipira - e a regional, por extensão - o espaço consagrado para o exercício produtor e reprodutor de uma memória sobre peões, boiadeiros e condutores atados ao mundo idílico rural, afirma Leite ${ }^{9}$. Compositores sul- matogrossenses revelam através da música regional o cotidiano das Comitivas Pantaneiras. "Onde a Comitiva Esperança chega já começa a festança através do Rio Negro, Nhecolândia e Paiaguás, vai descendo o Piqueri, o São Lourenço e o Paraguai", exalta Comitiva Esperança, de Paulo Simões, citando locais e rios mais conhecidos do Pantanal.

A música de Simões fala ainda das festas, principalmente quando o proprietário de alguma fazenda oferece pouso aos peões, em galpões ou varandas. "Tá de passagem, abre a porteira, conforme for prá pernoitar, se a gente é boa, hospitaleira, a Comitiva vai tocar moda ligeira que é uma doideira, assanha o povo e faz dançar, oh moda lenta que faz sonhar".

Em passo lento, enfrentando a precariedade das estradas, animais selvagens, climas adversos, doenças e humor da boiada, a comitiva segue. Por isso, a paciência é uma das qualidades exigidas pela profissão de peão, já que a condução de bois dura muitas marchas (dias). "Nossa viagem não é ligeira, ninguém

\footnotetext{
${ }^{9}$ LEITE, Eudes Fernando. Marchas na Hustória: comitivas, condutores e peões - boaiadeiros nas águas de Xarayes. Campo Grande: Ed.UFMS, 2003.
} 
tem pressa de chegar, a nossa estrada é boiadeira, não interessa onde vai dar", relata Comitiva Esperança.

Um estouro da boiada pode, por algum tempo, tirar a tranqüilidade da viagem. Tendo aprendido a laçar desde a infância, eles saem na captura do gado, em uma porfia - tipo de disputa entre os peões. Enquanto o perdedor sente-se humilhado, o vitorioso ganha prestígio:. "Cadê Ferreirinha, João Boiadeiro, Gonzaga Mineiro e o Negro Tião, que arriscam a vida em cima do arreio e em todos os rodeios chamavam atenção. Seus nomes famosos ficaram na história, passado e glórias na estrada de chão", lamenta Aurélio Miranda, em Estrada de Chão.

A travessia dos grandes rios do Pantanal significa sempre preocupação à comitiva, pois é arriscada, muitos animais podem morrer afogados. Entre novembro e março, os rios alagam grande parte da região. Comitiva Esperança mostra que, nesse período, certos locais têm que ser abandonados: "É, tempo bom que tava por lá, nem vontade de regressar, só vortemo, eu vô confessar, é que as águas chegaram em janeiro, descolamos um barco ligeiro, fomos pra Corumbá”.

Aurélio Miranda canta a tristeza do boiadeiro desempregado ou mesmo aposentado: "Meu par de esporas, meu laço e arreio que a tempo no meio das traias guardei; meu velho berrante enfeita a sala e ao lado as medalhas que colecionei; meu cavalo baio relincha no pasto, sentindo o desgaste que o tempo lhe fez".

Outro motivo de temor de condutores e peões é a redução do trabalho nas comitivas Com a inauguração da Rodovia Transpantaneira, o gado passou a viajar também em caminhões. Estrada de Chão expõe o ressentimento dos boiadeiros em relação à chegada do asfalto ao Pantanal. "Estrada de chão o seu tempo se foi, cadê a peonada poeira e bois. Cobriram de preto a estrada de chão e mais preto é o luto do meu coração. O passado morreu, só ficaram lembranças e morre comigo a doce esperança de ainda se ouvir, nas encruzilhadas, o berrante tocando, chamando a boiada".

Apesar de passar os dias conduzindo gado, o que se supõe ser uma rotina tranquila, os peões não têm uma vida fácil. Além de todos os contratempos que enfrentam na estrada, passam muito tempo longe de casa."A boiada ficou na estação, eu parti já tem mais de um verão. Meu cavalo nessa lida se acostumou, há tanto tempo que o tempo nem notou" cantam os irmãos Celito e Geraldo Espíndola, na música Pelo Rádio. A saudade que o boiadeiro sente da amada é 
transmitida pelas ondas do rádio. "Pelo rádio mandei avisar, tô voltando pra te encontrar. Eu bem sei que você se apaixonou, não duvidei, coração não se enganou. Saudade o que me faz regressar, cruzar o chão sob as luzes do luar".

\section{Romantismo, sofrimento e desamparo}

Nas viagens que realizamos acompanhando as comitivas da Dona Edith e do Mourão, nos pantanais de Nhecolândia-Abobral, Rio Negro e Paiaguás, foi possível chegar a algumas conclusões.

O mundo romântico das comitivas retratado nos livros e artigos de escritores regionais está chegando ao fim, se é que alguma vez existiu. Nas conversas de final de tarde, depois de ganhar a confiança dos peões, era comum ouvir frases como estas: "Sou analfabeto, só sei andar em cima do lombo de um cavalo", "andava atrás das comitivas com meu pai, nunca aprendi fazer outra coisa", "a gente começa a fazer isso e depois não tem como parar" e "estou muito velho para começar fazer outra coisa".

Igualmente o dia a dia das comitivas nada tem de romântico e prazeroso. O trabalho é de sol a sol, o isolamento das comitivas é angustiante, viver meses longe da família é sofrimento sem fim e enfrentar os perigos e as armadilhas pantaneiras é uma luta sem tréguas.

O desamparo dos peões talvez seja o problema maior. Sem registro em carteira - as comitivas são uma espécie de Terceiro Setor com muitos deveres e poucos direitos - o grande pavor é ficar doente ou sofrer algum acidente de trabalho. A única esperança é a aposentadoria por idade.

Não por caso, a maioria dos integrantes das comitivas é formada de peões adultos, alguns deles com mais de 60,70 anos. Um exemplo da falta de jovens nas Comitivas é dado por Wagner Mourão, o ex-fazendeiro que viu suas terras serem engolidas pela água, durante a construção da Transpantaneira: seus dois filhos ficam com a mãe, em Corumbá, "para estudar e conseguir uma vida melhor do que a minha". 